\title{
Fostering Graduate Student Research: Launching a Speaker Series
}

\begin{abstract}
The University of Arkansas Libraries' Special Collections, in partnership with the Graduate School and International Education, initiated a graduate student speaker series in 2018. The series is a professional development opportunity for graduate students who have done research in Special Collections. This case study provides an overview of the establishment of the series, ongoing efforts to recruit speakers and promote the series, and how the series was adapted for the virtual environment due to COVID-19.
\end{abstract}

By the time a student reaches the level of graduate education, they are expected to have well-developed research skills. While graduate students have been shown to be regular library users, their use of library resources and spaces does not always translate to graduate-level research skills. ${ }^{1}$ This presents libraries with an opportunity to create programming tailored to the needs of graduate students to address this gap. At the University of Arkansas (U of A), one of the Chancellor's eight Guiding Priorities, "Strengthening Graduate Education," became an area of interest for U of A Libraries' Special Collections Division (SC). Eager to provide graduate students the opportunity to develop themselves professionally, SC initiated a graduate student speaker series in 2018 in partnership with the Graduate School and International Education.

Held in person in its first three semesters, and virtually in the past three semesters, this case study illustrates the strategies libraries can employ to create community. The series provides graduate students a forum in which to present their research to the university community and receive feedback. To be eligible to speak in the series, each student must have used resources from SC as part of their work. The program highlights graduate student research, provides students with a venue for conducting and presenting their research, offers students an

1. DeeAnn Allison, "Measuring the Academic Impact of Libraries," portal: Libraries and the Academy 15, no. 1 (2015): 29-40; Colleen S. Harris, "The Case for Partnering Doctoral Students with Librarians: A Synthesis of the Literatures," Library Review 60, no. 7 (2011): 599-620; Amy Catalano, "Patterns of Graduate Students' Information Seeking Behavior: A Meta Synthesis of the Literature," Journal of Documentation 69, no. 2 (2013): 243-74. 
alternative to internships as a professional development opportunity, and draws attention to the university's unique resources. This case study describes the establishment of the series, ongoing efforts to recruit speakers and promote the series, and the impact of pivoting from an in-person program to virtual. The authors believe that this study may prove useful for libraries at other institutions hoping to engage graduate student populations more successfully, whether in person or in virtual spaces.

\section{Literature Review}

Library literature typically focuses on outreach to undergraduates who will be most in need of developing research skills. However, several studies have found that graduate students, while they may have acquired a basic level of research ability during their undergraduate career, also need opportunities to advance their research skills and develop professionally in their discipline's research area. Libraries typically provide internships and skill-specific workshops as professional development opportunities geared toward students. Providing opportunities for students to share their research remains a noticeable gap in the literature. This literature review is divided into four parts: the needs of graduate students; internships as a tool to professionalize students; adapting outreach to meet the emerging research skills and interests of graduate students; and lessons learned from pivoting in-person programming to a virtual platform.

Many studies have found that, although faculty admit graduate students to their programs with the expectation that the student has demonstrated their ability to complete the program successfully, attrition rates among graduate students (and especially among doctoral students) is especially high. ${ }^{2}$ One of the reasons often cited for these high attrition rates is that many graduate students are expected to be professional researchers but often enter programs underprepared to conduct graduate-level research in their discipline. ${ }^{3}$ Studies reveal that graduate students often consult faculty advisors but rarely consult academic librarians. ${ }^{4}$ This demonstrated lack of advanced research skills and reticence to work directly with librarians in favor of working with a faculty advisor presents academic libraries with an opportunity to create programming that encourages graduate students to work not only with library resources, but also to build relationships with and learn from academic librarians.

2. Harris, "The Case for Partnering Doctoral Students with Librarians," 599-620.

3. Catalano, "Patterns of Graduate Students' Information Seeking Behavior," 243-74; Harris, "The Case for Partnering Doctoral Students with Librarians."

4. Hannah Gascho Rempel, "A Longitudinal Assessment of Graduate Student Research Behavior and the Impact of Attending a Library Literature Review Workshop," College \& Research Libraries 71, no. 6 (2010): 532-47; Catalano, "Patterns of Graduate Students' Information Seeking Behavior." 
Special collections have relied heavily on internships as the primary form of professional development offered to students. While internships have been shown to be a "high impact practice," ${ }^{, 5}$ internship programs in special collections tend to focus on undergraduates who might be interested in pursuing a career in archives. ${ }^{6}$ Graduate archival education has long relied on incorporating internships or practicae as a part of professional development and training for future professionals, ${ }^{7}$ but these experiences are largely beneficial for a select group of graduate students, such as Master of Library and Information Science students planning a career in archives or history graduate students interested in learning more about archives outside their own archival research. Internships are typically unpaid, with students gaining skills or academic credit in place of salary. It behooves the profession to seek alternative methods for providing professional development opportunities to students, such as a speaker series.

Libraries have not always focused their efforts on graduate students, leading some in the field to pursue outreach targeted specifically to this group. ${ }^{8}$ The literature includes a few creative examples of outreach initiatives that foster student and faculty professional development. Outreach efforts to graduate students have included workshops and webinar series, ${ }^{9}$ and even a "dinner with a librarian" events. ${ }^{10}$ Academic outreach librarians at Virginia Commonwealth University led workshop and webinar series for graduate students over the course of four years and found that graduate students benefitted from single daylong events. ${ }^{11}$ Texas A\&M Librarians piloted "dinner with a librarian" to identify gaps in services to graduate students, especially in the humanities, and found that hosting targeted outreach with small groups helped them to scale their future outreach efforts. ${ }^{12}$

Speaker events are another popular way libraries have fostered connections with faculty and students while providing participants with professional speaking oppor-

5. Maggie Gallup Kopp, "Internships in Special Collections: Experiential Pedagogy, Intentional Design, and High-Impact Practice," RBM: Journal of Rare Books, Manuscripts, and Cultural Heritage 20, no. 1 (Spring 2019): 11-27.

6. Maggie Gallup Kopp and John M. Murphy, "Mentored Learning in Special Collections: Undergraduate Archival and Rare Books Internships," Journal of Library Innovation 3, no. 2 (2012): 50-62.

7. Donhee Sinn, "Collaborative Education between Classroom and Workplace for Archival Arrangement and Description: Aiming for Sustainable Professional Education," American Archivist 76, no. 1 (Spring/Summer 2013): 237-62.

8. Bettina Peacemaker and Martha Roseberry, "Creating a Sustainable Graduate Student Workshop Series," Reference Services Review 45, no. 4 (2017): 562-74; Tina Budzise-Weaver and Kathy Christie Anders, "Be Our Guest: Engaging Graduate Students through Specialized Outreach Events," Endnotes: The Journal of the New Members Round Table 7, no. 1 (2016): 1-12.

9. Peacemaker and Roseberry, "Creating a Sustainable Graduate Student Workshop Series."

10. Budzise-Weaver and Anders, "Be Our Guest."

11. Peacemaker and Roseberry, "Creating a Sustainable Graduate Student Workshop Series."

12. Budzise-Weaver and Anders, "Be Our Guest." 
tunities to add to their CVs. ${ }^{13}$ In her case study on a faculty speaker series, Kathleen Kasten cites a desire to highlight the library as a forum for interdisciplinary research, emphasizing the library as a partner in academic research and providing pretenured faculty with a professional development opportunity as the driving factors when creating the series. Structured as monthly one-hour events, the series was paired with heritage month themes. Faculty speakers were encouraged to invite their students to attend the events, which helped to increase attendance. ${ }^{14}$ Library speaker series established to date seem to be limited to faculty speakers rather than student speakers or presentations. Graduate students are a group wellsuited to take part in such series, as they, like early career faculty, have professional development needs related to research and publishing.

Library practitioners have started to reflect on and publish about their experiences of transitioning in-person programming to virtual spaces as a result of the COVID-19 pandemic, analyzing the benefits and drawbacks of each when striving to create community among their users. The University of Wyoming Libraries pivoted their planned in-person poetry series to virtual in spring and summer $2020 .{ }^{15}$ The authors found lower attendance for the virtual programs than previous in-person events. They attribute that result to Zoom fatigue and the timing of their programs, which took place in the first months of the pandemic. The authors recorded and uploaded their sessions to the Libraries' website. Recording, which is not always done for in-person events, will provide long-term access to the content, potentially growing interest in the program. Key lessons the authors learned can be applied to any virtual program, specifically: "be creative, stay flexible, communicate well, and to pay attention to detail." ${ }^{16}$

Expanding audience is another potential outcome of virtual programming. Inperson events are often limited to those who are in a specific geographic region, whereas a virtual audience can, as the Dallas Holocaust and Human Rights Museum found, more easily be national and global.17 Such an expanded community can reduce the intimacy characteristic of an in-person colloquium event, like the program described in the case study below. When public health is not a factor, practitioners should choose the format that best suits the type of community they seek to foster.

13. Kathleen Kasten, "Library as Forum: Building Relationships and Identity through Faculty Speaker Events," New Review of Academic Librarianship 24, no. 3 / 4 (2018): 404-15.

14. Kasten, "Library as Forum."

15. Stephen Boss et al., "Virtual Programming During COVID: What We Wished We Had Known in Advance," College and Research Library News 82, no. 7 (2021): 330-34.

16. Boss et al., "Virtual Programming During COVID," 333.

17. Felicia Williamson, "Adapting Archival Programming for a Virtual Environment," Archival Outlook (January/February 2021): 8, 18. 


\section{Establishing the Series}

Founded in 1871, the $\mathrm{U}$ of $\mathrm{A}$ is a public, land-grant research university located in Fayetteville, Arkansas. As the flagship campus of the University of Arkansas system, it is the largest university in the state, with an enrollment of 27,000 students. U of A Libraries include the David W. Mullins Library, which serves as the main research library on campus, as well as the Robert A. and Vivian Young Law Library, the Fine Arts Library, the Chemistry and Biochemistry Library, and the Physics Library. Mullins Library houses the Special Collections Division, founded in 1967 to serve as a resource for research into the history and culture of Arkansas and the surrounding region. The division includes approximately 14 FTE and has a robust outreach and instruction program. In a typical academic year prior to the COVID-19 pandemic, the division hosted 12 events a year and conducted about 70 instruction sessions. During the pandemic, the division scaled back their instruction and outreach to host about 6 events and 25 instruction sessions (all virtual) during the 2020-2021 academic year.

As a result of both the university's strategic plan and a consultant's recommendation to host a late-afternoon lecture series to promote research being done in SC to create a scholarly community, SC faculty explored the feasibility of hosting a graduate student speaker series. The Head of SC led the initiative for its first two years and then, with the onboarding of the Research \& Educational Services Archivist (RES Archivist) in 2019, the Head of SC stepped back from the series.

First, the Head of SC established eligibility criteria. As long as the students drew on materials held in SC as part of their research, they could present. To gauge interest, the Head of SC conducted a needs assessment with graduate student employees and leaders in the Graduate Professional Student Congress (GPSC). The group provided feedback about the best times of the day and week to host the series and shared suggestions about channels for recruiting speakers and promoting the series. The Head of SC then worked with the Associate Dean of the Graduate School and International Education to ensure there was campus support for the initiative. Partnering with the Graduate School and International Education was the first time SC initiated a program to directly benefit their students. The Head of SC presented the idea of the series to the GPSC Executive Committee in fall 2017. Throughout the spring semester, the Head of SC finalized the scope and goals of the program. These included providing graduate students with a professional development opportunity to add to their $\mathrm{CV}$; creating a community of scholars among graduate students, their faculty, and special collections; and highlighting graduate student research. SC then began to collaborate with the Director of Graduate Student Support to plan and promote the series launch in fall 2018. 


\section{Year 1: Academic Year 2018-2019 Recruitment and Promotion}

Beginning with the first speaker, the member of SC leading the program meets with each student individually before they agree to participate in the series, discusses the student's research, and offers guidance. While some students exhibit well-developed presentation skills, having one-on-one meetings with each student helps the librarian build rapport with the students and help those less familiar with explaining their research to further develop those skills.

To garner interest in the series, the Head of SC asked the incoming President of the GPSC, a well-known and well-respected member of the graduate student community on campus, to be the first speaker. A history $\mathrm{PhD}$ candidate, this student had used SC materials when writing a recently published article. He agreed to be the first speaker and recommended two other students-both in the history program - to speak later in the semester. Though all from the history program, the speakers' topics varied widely. One shared research about Christianity and the intersection with civil rights, another presented about the introduction of pesticides in government programs, and the third shared her journey to develop a dissertation topic about the civil rights movement in Arkansas. Each of the three talks took place on Thursday afternoons at 4 p.m. The day and time required SC to close early for researchers, as their only event space was the reading room. For each event, the division provided refreshments, which proved to be an inexpensive way to attract an audience.

Over the summer, the Head of SC worked with the Libraries' Director of Public Relations to create a flier template that could be emailed and printed to promote the series and each event. Each graduate student submitted a picture of themselves, the title of their talk, and a quote about their research experience. The Director of Public Relations included these details in an article about each event, published in the campus's daily e-newsletter and on the Libraries' website. The Director of Graduate Student Support included announcements about the events in her weekly email newsletter to students. As the series got underway, the Head of SC emailed faculty across campus to make them aware of the series and to encourage their students to attend.

\section{Assessment}

There was no formal assessment to evaluate the first year of the program, though the Head of SC did collect data about the number and demographics of the inperson audience (see table 1). While several graduate students came to each event, library faculty and staff made up most attendees. The third speaker in the fall gave her undergraduate students extra credit to attend, and many did. There was an up- 
tick in graduate student attendance during the spring semester, which also proved to be a successful way to recruit future speakers. Based on this first year, the Head of SC surmised that it would take some time before the goal of creating a scholarly community for graduate students would be met.

\begin{tabular}{|l|c|c|}
\hline \multicolumn{3}{|c|}{ TABLE 1 } \\
\hline \multicolumn{3}{|c|}{ Participation in 2018-2019 Events } \\
\hline Month & Attendees & Viewed Recording \\
\hline October 2018 & 18 & 117 \\
\hline November 2018 & 22 & 243 \\
\hline December 2018 & 37 & 198 \\
\hline February 2019 & 17 & 252 \\
\hline March 2019 & 18 & 184 \\
\hline April 2019 & 44 & 983 \\
\hline
\end{tabular}

To make the series accessible beyond the university community and as a promotional tool, the Head of SC used Facebook Live to stream the events. The high view count suggests that more people were interested in hearing the presentations than could attend in-person. Based on anecdotal feedback that the Head of SC received from the speakers and teaching faculty, the series had succeeded in providing students the opportunity to share their research and develop themselves professionally. Interested in understanding the impact a standing event had on the division, the Head of SC sought on feedback from the Research Services Unit staff. Due to the number of researchers impacted by closing the reading room to accommodate the events, the Head of SC decided to change the day and time for the series' second year.

\section{Year 2: Academic Year 2019-2020}

\section{Recruitment and Promotion}

The Research and Educational Services Archivist (RES Archivist) joined SC in summer 2019 and the Head of SC partnered with her when planning the series' second year. It had become clear that relying on graduate students to identify other potential speakers was not a sustainable recruitment strategy in the long run. This approach meant that speakers largely came from a single discipline, namely, history. To widen the representation of disciplines in the series, the authors began exploring new avenues for recruitment. These efforts included creating and promoting an online speaker application form on the SC website, speaking at a graduate student government meeting, and reviewing patron statistics to identify and reach out to graduate students who had conducted research in SC. 
In October 2019, the RES Archivist worked with the Libraries' web designers to create an online page and application form for the series. The page provides a brief description of the series, an explanation about eligibility to participate, and contact information, as well as links to live streams of past speakers' presentations. Having an online application form has opened new forms of recruitment, as the application can be linked within existing promotional efforts, including email newsletters from the Libraries and the Graduate School, blog posts on the library website, and social media posts publicizing the series. ${ }^{18}$

The authors attended a meeting of the GPSC in November 2019 to promote the series. After providing a brief overview of the series, they distributed event cards, which included information about the series, and answered questions from students about qualifying to present. The RES Archivist also began meeting with both the Director of Public Relations and the Director of Graduate Student Support to discuss the promotion for the series, and to provide each of them with information about each speaker and event for that semester.

To recruit students for the spring semester of 2020, the RES Archivist used a twoprong approach. First, she reviewed patron statistics to identify graduate students who had done research in SC. ${ }^{19}$ The RES Archivist then reached out to students via email. Because the RES Archivist worked regular shifts at the reading room research desk, she often interacted with graduate students during their research visits, or via email, helping to answer reference questions. This allowed for a second avenue for recruitment, as the RES Archivist emailed students she had worked with in the reading room or as part of instruction sessions to encourage them to participate. To date, this approach has been the most successful form of recruitment for the series.

To better accommodate researchers' needs in the reading room, the authors shifted the series to 4:30 p.m. on Tuesday, Wednesday, or Thursdays, depending on the graduate student's schedule.

\section{Assessment}

Overall attendance numbers grew during Year 2 (see table 2), with one presentation garnering over 100 attendees. Due to the COVID-19 pandemic, SC hosted only two events in the spring semester with a total attendance of 38 between the two events. Teaching faculty and graduate students began to consistently attend the events, as library staff participation waned slightly.

\footnotetext{
18. By the time the application form was made live, all speakers for the spring semester of 2020 had already been recruited. The application was used for the first time for the spring 2021 series, as recruitment efforts for the fall 2020 speakers differed from previous semesters.

19. Initially, staff recorded this data in LibInsights; but, following SC's transition to Aeon in August 2020 , Aeon became the primary tool for reviewing this information.
} 


\begin{tabular}{|c|c|c|}
\hline \multicolumn{3}{|c|}{ TABLE 2} \\
\hline \multicolumn{3}{|c|}{ Participation in 2018-2019 Events $^{20}$} \\
\hline Month & Attendees & Viewed Recording \\
\hline October 2019 & 14 & 51 \\
\hline November 2019 & 129 & 604 \\
\hline December 2019 & 24 & 13 \\
\hline January $^{21} 2020$ & 22 & NA \\
\hline February 2020 & 16 & 10 \\
\hline
\end{tabular}

The authors transitioned from Facebook Live to YouTube Livestreaming, as it was more easily accessible for viewers who did not have a Facebook account and because the authors theorized that YouTube videos would be more discoverable and easier to link to on the SC website. In addition, YouTube allowed for the pairing of PowerPoint slides with the livestreams, a feature Facebook Live did not offer. YouTube views varied widely from speaker to speaker. While there is no concrete evidence for the discrepancy among views, it is likely that the November speaker, who was discussing integration in Little Rock, received far more views than other speakers due to the timeliness of the topic and his own personal network. Overall, the authors found that YouTube generated fewer views than Facebook Live had. This may be because the SC online audiences were not as aware of the YouTube livestreams, since they do not appear in a feed the way Facebook Live videos do. It may also be because Facebook Live counts views of a few seconds that occur as someone scrolls through their feed but does not watch for a substantial amount of time.

To solicit feedback from student speakers, the authors took two of the speakers to lunch in December 2019. The students emphasized the benefits of the series, including the opportunity to present their research and practice public speaking. They suggested creating promotional videos for the series in which the upcoming speaker could give a quick summary of their upcoming presentation, interspersed with images of collections they used in their research. The students also recommended offering a stipend to attract speakers and further incentivize participation. ${ }^{22}$ Getting feedback from two recent speakers helped the authors to determine if they were achieving the series' goals.

20. Viewed Recording, refers to YouTube viewer counts, as of March 1, 2021.

21. Due to technical difficulties, no recording was made for this presentation.

22. This series suffers one of the same limitations as the traditional archival internship structure, in that speakers were not paid for their participation. In some ways, the series is distinct from an internship in that students are already undertaking research in SC as part of their studies-generally as research toward a thesis or dissertation. In this way, the series offers students a way to gain experience presenting the work they were already engaged in and receiving feedback on it prior to submitting it as part of their graduate coursework. 
As part of the promotion for each talk, the authors encourage the speaker to reach out to their network to help draw attendees. Speakers' networks on campus and in the community proved to be the biggest influence on number of attendees. Though the authors actively promoted the series, more faculty, students, and community members attended the presentations when the speaker had personally invited them or they had seen a post about the event on the speaker's social media feed. For example, one of the speakers, who discussed her use of cookbooks and the recipes she found, drew many people from her church and her community groups. The student speaking about the segregation of Little Rock is well-known on campus and well-respected among faculty and students. Additionally, the speaker's topic had seen a resurgence in interest at the time due to a decision by the State Board of Education that allowed predominantly white schools in Little Rock to self-govern while the state maintained control over predominantly minority schools. As a result, more than 100 people came to hear his presentation and show their support. By contrast, several graduate students who were newer to the area, and lacked the extensive networks that some of their peers had, drew smaller audiences based on people's interest in the topic rather than in support of the specific speaker.

At the end of the fall semester, the Head of SC stepped back from her role as co-coordinator to provide the RES Archivist with experience managing a substantial outreach initiative. Incorporating the feedback from the previous year's speakers, the RES Archivist worked with the Libraries' Director of Public Relations to create promotional videos for Instagram, featuring February's and March's speakers. In mid-March, SC closed to the public due to the pandemic, and the RES Archivist decided to postpone the April speaker until the fall semester. Over the summer it became clear that SC would not host in-person events during the 2020-2021 academic year, and the RES Archivist began planning to adapt the series to a fully online environment. This process consisted of adaptations in three main areas: recruitment for the series, the tools used to facilitate the online version of the series, and the logistics of using those tools strategically and effectively.

\section{Year 3: Academic Year 2020-2021 Recruiting for Virtual Events}

Recruiting new speakers for the series became more difficult as a result of the division's spring closure and limited hours in the fall. The student who had planned to speak in April agreed to present virtually in November, and the RES Archivist used previously successful strategies to recruit a $\mathrm{PhD}$ candidate in English Rhetoric and Composition. 


\section{Facilitating Virtual Events}

Preparing for the virtual series was very different from preparing for in-person events and required use of online tools in new ways. The RES Archivist primarily used three tools to run the series online: Eventbrite, Zoom, and YouTube. She used Eventbrite for registration, which sent automated emails to registrants with event details and reminders. The RES Archivist hosted the events as Zoom meetings and followed the recommendations for online events outlined in the RBMS Diversity Committee's "Zoom Security for Public Events" documentation. ${ }^{23}$ She also recruited an SC Zoom co-host for each event, who could continue to run Zoom if unexpected technical issues arose. Unlike in-person events, the RES Archivist asked each speaker to prerecord their presentations in Zoom, to avoid technical difficulties on the day of the presentation and to allow for ease of captioning for accessibility. The RES Archivist continued to livestream the presentations, using Zoom on the day of the synchronous event rather than YouTube Live. She recorded the session that included her introductory remarks, the graduate student speaker's presentation, and the question-and-answer session. As in previous semesters, the RES Archivist uploaded each recording to YouTube and sent the participants the link following the presentation.

The virtual events afforded speakers opportunities to share their research and archival sources in new and engaging ways. One speaker integrated short videos of herself paging through archival materials, bringing a sense of the physical materials into the virtual presentation. A speaker whose work addressed climate change created her own collection of artists' books, drawing on the materials she used in her research in SC. Being able to see these creative outputs up close on screen, made harder when sitting in person, brought participants into the archive and provided a glimpse into what it means to do archival research.

\section{Assessment}

The move online increased engagement with the series-both in attendance at synchronous events and in views of the recorded events on YouTube (see table 3).

\begin{tabular}{|l|c|c|c|}
\hline \multicolumn{4}{|c|}{ TABLE 3 } \\
\hline \multicolumn{4}{|c|}{ Participation in 2020-2021 Events ${ }^{24}$} \\
\hline Month & Registrants & Attendees & Viewed Recording \\
\hline September 2020 & 63 & 37 & 61 \\
\hline November 2020 & 36 & 20 & 19 \\
\hline March 2021 & 40 & 23 & 257 \\
\hline
\end{tabular}

23. Alison Clemens, email message to RBMS list serv, October 5, 2020.

24. Viewed Recording, refers to YouTube viewer counts, as of March 1, 2021. 
As confirmed in the emerging literature about programs that pivoted to online platforms during the pandemic, these virtual events allowed for broader participation than those who would typically be able to attend in person. Registrants for speaker events during academic year 2020-2021 came from three countries (the United States, Canada, and South Africa), and from 18 US states. The RES Archivist also employed Eventbrite's automated email function to send out an online event survey following each event, anticipating that participants might be more likely to fill out an online survey when they had interacted with the event fully online, as opposed to an in-person event. However, only one attendee completed the survey following the September speaker, and no attendees completed the survey following the November speaker.

While number of attendees serves as a standard metric in case studies across library literature and was therefore employed in this case study, such a metric is not always necessarily the most meaningful measure of success. The expanded reach of virtual events as evidenced by registrants attending from a much wider geographical range than the immediate local community signal expanded engagement with SC. Additionally, the relationships the authors have created with graduate students in different departments across campus and the traction the series is gaining are meaningful markers of success. For example, a student who participated in the series in fall 2020 was hired as an instructor following graduation and immediately reached out to get her classes on the calendar for Special Collections instruction for the fall semester. This speaks to the long-term impact of the program beyond the numbers of attendees at a single program.

\section{Challenges and Future Plans}

We anticipate that assessment will continue to be a challenge, even with the ongoing use of Eventbrite, as evidenced by low engagement with a postevent survey. In future semesters, the RES Archivist is considering asking graduate students who participated in the series to provide feedback on their experiences via an online form to ensure that the series is accomplishing its goals. As the reading room continued operating with reduced hours through 2021, the RES Archivist anticipates that recruitment will continue to be a challenge, as those hours will impact the number of graduate students conducting research.

To address recruitment challenges, in collaboration with the Libraries' Director of Public Relations, division staff plan to be more proactive in publicizing the application process for the series. This would include adding the application link or QR code to flyers posted around campus and creating promotional cards with the application link that could be handed out at events put on by the Graduate School and International Education or handed out to interested students following a series presentation. The RES Archivist hopes that this will engage graduate students who 
have not yet done research in SC and encourage them to do so, rather than continue to rely on a pool of students who are already aware of SC as a resource.

Virtual events also made it challenging to foster a sense of community among graduate students, their faculty, and SC. Because more graduate students and faculty attended the virtual events than in-person events, examining how virtual communities can be sustained will be important as the series continues. One potential opportunity is to create a Facebook group that all current and former series speakers could be invited to join, thereby encouraging an online community that could outlast students' single-semester participation in the program. This model has been explored by another of the Libraries' initiatives, the Arkansas Folk and Traditional Arts Community Scholars Program, which has a private Facebook group for community members from across the state who have participated in the Community Scholars training program. The RES Archivist has also begun planning an Archival Research Workshop series for graduate students in the hopes of fostering community among students leading up to students' potential participation in the speaker series. The workshop would offer a variety of sessions on different topics related to archival research, with a catered lunch. The RES Archivist sent a survey out to previous participants in the series to gauge what type of support would have been most helpful to them leading up to their participation in the series, and she is currently incorporating that feedback into plans for the Workshop series, which will likely take place for the first time in the summer or fall semester of 2022. At the same time, SC will consider how physical spaces can best strengthen the community as it embarks on renovation planning.

Although it presented challenges, the pivot to virtual programming offers several opportunities for the RES Archivist to integrate the aspects of virtual programs that most benefited the series as SC transitions to holding in-person or hybrid events in the future. Key benefits include attracting a wider audience not tied to our physical location; gathering demographic data about attendees; encouraging creative presentation styles and content as evidenced by the reading room videos and other experiential elements speakers incorporated. The RES Archivist values the demographic data Eventbrite captures about registrants, and she plans to continue to use this tool for registration even after the series returns to in-person events. She would also like to customize the Eventbrite data to collect information on what academic departments attendees are coming from. Such a data point will enable the RES Archivist to reach out to specific departments at the university as part of her promotion and recruitment efforts.

Providing a stipend to all speakers will be the biggest change as the series continues. In keeping with a divisionwide decision to begin paying all interns, SC will draw on the division's endowment to provide an honorarium to all future graduate student speakers. SC seeks to compensate the graduate students for their time, 
much in the same way they provide honoraria to other presenters. Not only does this demonstrate to the students how much the division values the students' participation, but the authors hope that offering the honoraria will also help to further incentivize the program and encourage participation.

\section{Conclusion}

The U of A Special Collections Graduate Student Speaker Series, begun in 2018 as an opportunity for graduate students to develop themselves professionally outside of traditional internships, has evolved over time as the authors explored new ways to recruit students, encourage research in SC from a range of disciplines, and make the series a meaningful opportunity for both student speakers and their audiences. In its first three years, the series accomplished two of its three main goals: providing graduate students with a professional development opportunity to add to their CV and highlighting graduate student research. The division has fostered a positive relationship with the Graduate School and International Education and that partnership will continue to be crucial to the series' ongoing success. As a result of the series, SC has become known as a source of support for graduate students on campus, not only when conducting research but also when seeking a platform to draw attention to current events and challenging conversations. The authors plan to continue to pursue new avenues to create community among graduate students as the series evolves.

COVID-19 presented the authors with unique challenges in transitioning an in-person event to a virtual one; but, in meeting this challenge, the authors were able to learn about and use new tools, such as Eventbrite, which they plan to use even after in-person events resume to gather more detailed data about the series' audience. Given the protracted nature of the COVID-19 pandemic, few libraries have had the opportunity to host or publish about their experiences with hybrid programs drawing on lessons learned from exclusively virtual events. Such a hybrid approach would offer participants the opportunity to engage with the content either in person or virtually.

This case study has outlined a program led by a specific library division within a specific academic institution. The authors believe that this case study and the experience it describes may offer other libraries, including library departments outside special collections, inspiration for similar projects that can be adapted to fit a specific institution's needs. The literature reveals that libraries are often underused by graduate students, necessitating new initiatives aimed at engaging graduate students with the libraries, possibly through some form of programming. ${ }^{25}$ However, examples of such programming are still limited. Therefore, the authors hope that the graduate student speaker series outlined in this case study will add a positive record to this growing body of work.

25. Peacemaker and Roseberry, "Creating a Sustainable Graduate Student Workshop Series"; BudziseWeaver and Anders, "Be Our Guest." 